\title{
28 Research Square \\ A Critical Period for Learning and Plastic Changes at Hippocampal CA1 Synapses
}

\section{Yuya Sakimoto}

Yamaguchi University Graduate School of Medicine

D Mitsushima ( $\nabla$ mitsu@yamaguchi-u.ac.jp )

Yamaguchi University Graduate School of Medicine

\section{Research Article}

Keywords: AMPA receptor, GABAA receptor, contextual learning, synaptic plasticity, postnatal development

Posted Date: November 23rd, 2021

DOI: https://doi.org/10.21203/rs.3.rs-1041632/v1

License: (1) This work is licensed under a Creative Commons Attribution 4.0 International License. Read Full License

Version of Record: A version of this preprint was published at Scientific Reports on May 3rd, 2022. See the published version at https://doi.org/10.1038/s41598-022-10453-z. 


\section{Abstract}

Postnatal development of hippocampal function has been reported in numerous mammalian species, including humans. To obtain a synaptic evidence, we analyzed developmental changes in plasticity after an inhibitory avoidance task in rats. Learning performance was low in infants (postnatal 2 weeks) but clearly improved from the juvenile period (3-4 weeks) to adulthood ( 8 weeks). One hour after the training, we prepared brain slices and sequentially recorded miniature excitatory postsynaptic currents (mEPSCs) and inhibitory postsynaptic currents (mIPSCs) from the same hippocampal CA1 neuron. Although the training failed to affect the amplitude of either mEPSCs or mIPSCs at 2 weeks, it increased mEPSC, but not mIPSC, amplitude at 3 weeks. At 4 weeks, the training had increased the amplitude of both mEPSCs and mIPSCs, whereas mIPSC, but not mEPSC, amplitude was increased at 8 weeks. Because early-life physiological functions can affect performance, we also evaluated sensory-motor functions together with emotional state and found adequate sensory/motor functions from infancy to adulthood. Moreover, by analyzing performance of rats in multiple hippocampal-dependent tasks, we found that the developmental changes in the performance are task dependent. Taken together, these findings delineate a critical period for learning and plastic changes at hippocampal CA1 synapses.

\section{Highlights}

uWe identified a critical period of contextual learning between 16 and 22 days of age.

पThe performance was accompanied with the training-induced synaptic diversity.

पThe training diversified CA1 synapses in juveniles and adults, but not in infants.

पBattery tests confirmed sufficient sensory/motor functions in examined periods.

[In emotional state, infants were more unanxious and adults were more exploratory.

\section{Introduction}

The hippocampus is a region that is central to episodic memory formation [1] and processes spatiotemporal information $[2,3]$ related to a specific event $[4,5]$. Postnatal experience enhances the development of the hippocampus, although the function is not yet mature in infants $[6,7,8,9,10]$.

Miles [11] first published evidence that human adults could not recall specific events from early childhood, which is termed infantile amnesia $[7,8,9,10]$. In rats, Campbell and Campbell [6] showed rapid forgetting of contextual memory on postnatal day 18 . In turn, the retention was clearly improved if the task was performed on postnatal days 38,54 , and 100 . Postnatal-day-18 rats consistently showed this deficit [6,12], with improvement in their performance observed after postnatal day 23 [12,13]. However, the learning behavior should be evaluated precisely, because insufficient sensory or motor performance could affect task performance. 
Synaptic contacts in hippocampal CA1 neurons continuously increase in the first several weeks of life in rats $[14,15,16]$. Spine density dramatically increases from postnatal days 7 to 28 , especially from days 7 to 21 , expanding by 3 -fold [17]. Moreover, the magnitude of long-term potentiation (LTP), which is a cellular substrate for learning and memory, dramatically increases from postnatal days 10 to 20 , with the increase persisting up to day 60 [18]. A recent brain-wide analysis of synapses across the lifespan of rats further demonstrated that the molecular/morphological diversity of excitatory synapses was dramatically increased within the first postnatal month, especially in the hippocampus [19].

Insertion of membrane AMPA receptors is a major mechanism underlying the LTP in CA1 pyramidal neurons $[20,21]$. Regarding the causal relationship, hippocampal-dependent contextual learning not only requires synaptic delivery of AMPA receptors, but also strengthens $G_{A B A}$ receptor-mediated inhibitory synapses onto neurons [22,23]. Moreover, this learning strengthens both excitatory and inhibitory synapses in different ways in individual CA1 neurons, thus producing a broad variety of synaptic input across cells in juvenile males $[24,25]$. Using the same experimental protocol, here we evaluated a critical change in learning together with the plastic change that occurs from infancy to adulthood.

\section{Materials And Methods}

\section{Animals}

Male Sprague Dawley rats were used in this study (Table 1). After weaning, same-sex groups of 2-3 rats were housed in plastic cages (length: $25 \mathrm{~cm}$; width: $40 \mathrm{~cm}$; height: $25 \mathrm{~cm}$ ) at a constant temperature of $23^{\circ} \mathrm{C} \pm 1^{\circ} \mathrm{C}$ under a constant cycle of light and dark (lights on: 8:00 am to 8:00 pm). We counted the parturition day as postnatal day 1 , and litters were reduced to 10 pups per cage on day 2 . The pups were weaned on postnatal day 20 or 21 and housed in group cages with free access to food and water. The rats were individually housed at least $24 \mathrm{~h}$ prior to the experiments, to avoid any episodic experience. Food (MF, Oriental Yeast Co. Ltd, Tokyo Japan) and tap water were available ad libitum in all experimental periods. All animal housing and surgical procedures followed the guidelines of the Institutional Animal Care and Use Committee of Yamaguchi University. All experimental procedures were approved by the Institutional Animal Care and Use Committee of Yamaguchi University (Approval No. 04S02). the These guidelines comply with the Guide for the Care and Use of Laboratory Animals published by the National Institutes of Health (NIH Publication No. 85-23, revised 1996). The study reported in accordance with ARRIVE guidelines.

Table 1 Postnatal groups and body weight

Postnatal weeks Postnatal days Body weight $(\mathrm{g}) \quad$ Number of rats 
2

3

4

8
$16.0 \pm 0.1$

$21.5 \pm 0.1$

$28.6 \pm 0.2$

$56.1 \pm 0.2$
$34.7 \pm 0.7$

$53.2 \pm 1.0$

$103.4 \pm 2.2$

$307.2 \pm 6.3$
73

49

59

49

Data are the means \pm SEM.

\section{Inhibitory avoidance (IA) task}

The IA training apparatus (length: $33 \mathrm{~cm}$; width: $58 \mathrm{~cm}$; height: $33 \mathrm{~cm}$ ) was a two-chambered box consisting of a lit safe side and a dark shock side separated by a trap door (Fig. $1 A ;[22,23]$. For training, rats were placed in the lit side of the box, facing the corner opposite the door. After the trap door was opened, the rats could enter the dark box at will. The latency before entering the novel dark box was measured as a behavioral parameter (latency before IA learning, Fig. 1B). Soon after the animals entered the dark side, we closed the door and applied a scrambled electrical foot shock (1.6 mA, $2 \mathrm{~s})$ via electrified steel rods placed in the floor of the box. The rats were kept in the dark compartment for $10 \mathrm{~s}$ before being returned to their home cage. Untrained control rats were not moved from their home cages. Moreover, regarding the yoked controls, the unpaired control rats (foot shock only) were housed in the shock cage and subjected to the same scrambled electrical foot shock without any contextual experience. The walk-through control rats were placed in the IA training apparatus and allowed to explore for 1 min, without shock delivery. We confirmed the absence of mEPSC and mIPSC changes in juvenile animals exposed to the untrained, unpaired, or walk-through conditions [23].

Thirty minutes after the procedure described above, the rats were placed in the lit side of the box. The latency before entering the dark box was measured as an indicator of learning performance (latency after IA learning, Fig. 1B).

\section{Electrophysiological recording of slice-patch clamping}

We have previously reported the detailed technical protocol of the slice-patch clamp technique used for analyzing training-induced synaptic plasticity, with a short demonstration movie [67]. Briefly, $1 \mathrm{~h}$ after the delivery of the paired foot shock, rats were anesthetized with pentobarbital and acute brain slices were prepared $[22,23]$. We used naive rats as the untrained group, all of which were injected with the same dose of anesthesia in their home cage. For the whole-cell recordings [68], the brains were quickly perfused with ice-cold dissection buffer $\left(25.0 \mathrm{mM} \mathrm{NaHCO}_{3}, 1.25 \mathrm{mM} \mathrm{NaH}_{2} \mathrm{PO}_{4}, 2.5 \mathrm{mM} \mathrm{KCl}, 0.5 \mathrm{mM} \mathrm{CaCl}_{2}, 7.0 \mathrm{mM}\right.$ $\mathrm{MgCl}_{2}, 25.0 \mathrm{mM}$ glucose, $90 \mathrm{mM}$ choline chloride, $11.6 \mathrm{mM}$ ascorbic acid, and $3.1 \mathrm{mM}$ pyruvic acid) and gassed with $5 \% \mathrm{CO}_{2} / 95 \% \mathrm{O}_{2}$. Coronal sections (target CA1 area: $\mathrm{AP},-3.8 \mathrm{~mm}, \mathrm{DV}, 2.5 \mathrm{~mm}, \mathrm{LM}, \pm 2.0 \mathrm{~mm}$; [69] were prepared (350 $\mu \mathrm{m}$, Leica vibratome, VT-1200) in dissection buffer and transferred to 
physiological solution $\left(22^{\circ} \mathrm{C}-25^{\circ} \mathrm{C} ; 114.6 \mathrm{mM} \mathrm{NaCl}, 2.5 \mathrm{mM} \mathrm{KCl}, 26 \mathrm{mM} \mathrm{NaHCO}_{3}, 1 \mathrm{mM} \mathrm{NaH}_{2} \mathrm{PO}_{4}, 10\right.$ $\mathrm{mM}$ glucose, $4 \mathrm{mM} \mathrm{MgCl}_{2}$, and $4 \mathrm{mM} \mathrm{CaCl}_{2}, \mathrm{pH} 7.4$ ) gassed with $5 \% \mathrm{CO}_{2} / 95 \% \mathrm{O}_{2}$. The recording chamber was perfused with physiological solution at $22^{\circ} \mathrm{C}-25^{\circ} \mathrm{C}$.

Patch recording pipettes (4-7 M $)$ ) were filled with intracellular solution (127.5 mM cesium methanesulfonate, $7.5 \mathrm{mM} \mathrm{CsCl}, 10 \mathrm{mM}$ HEPES, $2.5 \mathrm{mM} \mathrm{MgCl}_{2}$, $4 \mathrm{mM} \mathrm{Na}_{2}$ ATP, $0.4 \mathrm{mM} \mathrm{Na}_{3} \mathrm{GTP}, 10 \mathrm{mM}$ sodium phosphocreatine, and $0.6 \mathrm{mM} \mathrm{EGTA}$ at $\mathrm{pH}$ 7.25). Whole-cell recordings were obtained from CA1 pyramidal neurons from the rat hippocampus using an Axopatch $700 \mathrm{~A}$ amplifier (Axon Instruments). The whole-cell patch-clamp data were collected using a Clampex 10.4 instrument, and the data were analyzed using the Clampfit 10.4 software (Axon Instruments).

\section{Miniature postsynaptic current recordings}

We have previously reported the detailed technical protocol of the miniature postsynaptic current recording $[22,23]$. mEPSCs are thought to correspond to the responses elicited by the presynaptic release of a single vesicle of glutamate. In contrast, mIPSCs are thought to correspond to GABA. Increased mEPSC and mIPSC amplitudes reflect the strengthening of postsynaptic transmission, whereas increased event frequency reflects an increased number of functional synapses or presynaptic release probability.

For the miniature recordings, we added a $\mathrm{Na}^{+}$channel blocker $(0.5 \mu \mathrm{M}$ tetrodotoxin) to the physiological solution. The mEPSCs ( $-60 \mathrm{mV}$ holding potential) and mIPSCs ( $0 \mathrm{mV}$ holding potential) were recorded sequentially for $5 \mathrm{~min}$ in the same CA1 neuron. The miniature events were detected using the Clampfit 10.4 software (Axon Instruments), and the events above 10 pA were used in the analysis. We recorded for at least $5 \mathrm{~min}$, to determine the event frequency of mEPSCs or mIPSCs. The amplitudes of the events were averaged to obtain the mean amplitude. Bath application of an AMPA receptor blocker (CNQX, 10 $\mu \mathrm{M}$ ) or $\mathrm{GABA}_{\mathrm{A}}$ receptor blocker (bicuculline methiodide, $10 \mu \mathrm{M}$ ) consistently blocked the mEPSC or mIPSC events, respectively.

\subsubsection{Paired-pulse stimulation}

We have previously reported the detailed technical protocol of the paired-pulse stimulation [24]. To analyze presynaptic plasticity at excitatory synapses, we added $0.1 \mathrm{mM}$ picrotoxin and $4 \mu \mathrm{M} 2$ chloroadenosine to the physiological solution and performed paired-pulse stimulation at $-60 \mathrm{mV}$. To analyze presynaptic plasticity at inhibitory synapses, we added $10 \mu \mathrm{M} C N Q X$ to the perfusate and performed paired-pulse stimulation at $0 \mathrm{mV}$. To evaluate the paired-pulse ratio from the EPSC or IPSC average, 50-100 sweeps were recorded with paired stimuli at 100-ms intervals. We placed the stimulation electrode in either the stratum oriens (basal) or stratum radiatum (apical), to record evoked somatic currents. The ratio of the second amplitude to the first amplitude was calculated as the paired-pulse ratio $[23,70]$.

\section{Self-entropy analysis}


Based on the Shannon entropy, we quantified the synaptic diversity by measuring the population differences in $\mathrm{mE}(\mathrm{I}) \mathrm{PSC}$ amplitude and frequency compared with untrained rats [24,25]. We used a standard spreadsheet software (Excel 2010, Microsoft Co., Redmond, WA, USA) to calculate the selfentropy per neuron. First, we obtained four miniature parameters (i.e., mean mEPSC amplitude, mean mIPSC amplitude, mean mEPSC frequency, and mean mIPSC frequency) in individual CA1 pyramidal neurons. Subsequently, we determined the distribution of the appearance probability of four miniature parameters separately using one-dimensional kernel density analysis. The geometric/topographic features of the appearance probability were calculated using a kernel density analysis. Let $X_{1}, X_{2}, \ldots, X n$ denote a sample of size $n$ from real observations. The kernel density estimate of $P$ at the point $x$ is given by the following equation:

$$
P_{n}(x)=\frac{1}{n h} \sum_{i=1}^{n} K\left(\frac{x-X_{i}}{h}\right)
$$

where $K$ is a smooth function called the Gaussian kernel function and $h>0$ is the smoothing bandwidth that controls the amount of smoothing. We chose Silverman's reference bandwidth or Silverman's rule of thumb [71,72], which is given by the following equation:

$h=0.9 A n^{-1 / 5}$,

where $A=\min$ (standard deviation, interquartile range/1.34). By normalizing the integral value in untrained controls, we identified the distribution of the appearance probability at any point. Subsequently, we calculated the appearance probability at selected points. All data points for probability in untrained and trained rats were converted to self-entropy (bits) using the Shannon entropy concept, as defined in the Information Theory [73].

To perform calculations using the spreadsheet software, the data for four miniature parameters were summarized in four different sheets, and we obtained the bandwidth $(h)$ of individual parameters in the untrained group using the following formula: [= 0.9 STDEV (neuron 1, neuron $2, \ldots$ neuron $M$ ) / COUNT (neuron 1, neuron 2,... neuron $M)^{\wedge}(1 / 5)$ ]. Then, using the data from the untrained group, we calculated the distribution of the appearance probability as follows:

- The probability distribution of the first datum for a parameter (neuron 1) was calculated using the formula [= EXP $\left(-\left(((\text { data of neuron } 1 \text { - any point }) / h)^{\wedge} 2 / 2\right)\right) /$ SQRT $\left.(2 \times \mathrm{PI}())\right]$.

- Moreover, the probability distribution of the second datum for the parameter (neuron 2) was calculated using the formula [= $\left.\operatorname{EXP}\left(-\left(((\text { data of neuron } 2 \text { - any point }) / h)^{\wedge} 2 / 2\right)\right) / \operatorname{SQRT}(2 \times \operatorname{PI}())\right]$.

- Similarly, the probability distribution of the $N$ datum for the parameter (neuron $N$ ) was calculated using the formula [= EXP $\left.\left(-\left(((\text { data of neuron } N \text { - any point }) / h)^{\wedge} 2 / 2\right)\right) / \operatorname{SQRT}(2 \times \operatorname{PI}())\right]$. 
- All probability distributions from neurons 1 to $N$ were summed, and the integral value was normalized to 1 .

Based on the probability distribution, we calculated the individual appearance probability of all recorded neurons. Subsequently, the appearance probability of the neuron was converted to the self-entropy using Shannon's formula (= -LOG [appearance probability of the neuron, 2]) (Fig. $3 A, B$ ). For graphic expression, the distribution was visualized two-dimensionally in the $\mathrm{R}$ software environment ( $\mathrm{R}$ Foundation for Statistical Computing, Vienna, Austria) (Figs 2B, C and 3A, B).

\section{Behavioral test battery}

Behavioral tests were performed in the following sequence: open field, object recognition, social preference, social recognition task, social interaction, object-in-place task, light-dark box test, visual placing response test, hanging wire test, Y-maze spontaneous alternation, contextual fear conditioning, and flinch and jump. We used different sampling rats in social preference, social recognition task and social interaction, and different object in object recognition and object-in-place task. The between tests interval was at least $60 \mathrm{~min}$. Rats were habituated to the testing room $30 \mathrm{~min}$ prior to testing and the apparatus was cleaned with $70 \%$ ethanol between each trial.

\section{Visual placing response test}

To evaluate the sense of sight, we administered the visual placing response test [74,75]. In this test, the rat was suspended by its tail and then lowered toward a black foam plate placed on the front side of its head, without any contact to the vibrissae. Normally, when the head of a rat is lowered to near the edge of the plastic plate, the animal turns its head and trunk and extends its forelimbs to place them on the plate. The success ratio was calibrated to whether the rat successfully placed its forelimbs on the plate [76].

\section{Hanging wire test}

To evaluate basic motor function, we administered the hanging wire test. Rats were placed on a meshed wire, and the wire was turned upside down. The latency was tracked from the beginning of the test until the rats fell to the ground.

\section{Open field test}

To evaluate emotional state and spontaneous locomotor activity, we used the open field test. The center area (diameter $36 \mathrm{~cm}$ ) and the peripheral area (diameter $60 \mathrm{~cm}$ ) of the gray circle floor were lined. After the audio-visual recording, we measured the time spent in the center area and the distance traveled over $5 \min [9]$.

\section{Flinch and jump test}

To evaluate pain sensibility, we performed the flinch and jump test [77]. Rats were placed individually in the fear-conditioning chamber. The conditioning chamber (length: $25 \mathrm{~cm}$; width: $31 \mathrm{~cm}$; height: $42 \mathrm{~cm}$ ) 
was constructed of clear Plexiglass on the top, front, and back. The floor had 18 stainless steel bars (4 $\mathrm{mm}$ in diameter; 15-mm spacing), to deliver the scrambled shocks produced by a stimulator (LE100-26 Shocker, Panlab, Cornellà, Spain). After a 3-min period of habituation to the test box, shock titrations continued to increase in a stepwise manner ( $0.05 \mathrm{~mA}$ increments; range, 0.05-0.6 $\mathrm{mA})$. In this way, the "flinch" and "jump" thresholds (in $\mathrm{mA}$ ) were defined for each rat. The interval between shocks was 2 min, and each animal was tested only once at each intensity. The behavior of each rat was recorded through a front digital video recording camera. The "flinch" threshold was defined as the lowest shock intensity that elicited a detectable response. The "jump" threshold was defined as the lowest shock intensity that elicited the simultaneous removal of at least three paws (including both hind paws) from the grid [78]. The "vocalization" threshold was defined as the lowest shock intensity that led to a detectable audible vocalization in response to shock stimuli.

\section{Light-dark box test}

To evaluate anxiety and the exploration of a novel environment, we administered the light-dark box test [79,80,81]. The light-dark box (length: $48 \mathrm{~cm}$; width: $20 \mathrm{~cm}$; height: $23 \mathrm{~cm}$ ) was constructed of light and dark compartments separated by a sliding door (width: $7 \mathrm{~cm}$; height: $8 \mathrm{~cm}$ ). The rats were placed in the center of the dark box and allowed to explore for $5 \mathrm{~min}$. Then, the sliding door was opened, and they explored both boxes for 5 min (Fig. 5G).

\section{Social interaction test}

To evaluate the social interaction with an unfamiliar partner (stranger; same strain, sex, and age), we used the social interaction test [82]. Prior to the task, we habituated the rats to an empty open field arena (diameter: $45 \mathrm{~cm}$; height: $45 \mathrm{~cm}$ ) for $5 \mathrm{~min}$. Five minutes later, the rats were placed in the center of the arena again. One minute later, we placed an unfamiliar partner in the center of the arena, to assess social interaction for $5 \mathrm{~min}$ (Fig. $\mathbf{5 H}$ ). Sniffing behavior was defined as the animal directing its nose toward or touching the partner.

\section{Social preference test}

To evaluate social preference, we used a U-field two-choice box $[83,84,85]$. The U-field box consisted of two symmetrical rectangular fields that were defined by partitioning an open field (length: $45 \mathrm{~cm}$; width: $45 \mathrm{~cm}$; height: $45 \mathrm{~cm}$ ) with a wall (length: $20 \mathrm{~cm}$; height: $45 \mathrm{~cm}$ ). Prior to the task, we habituated the rats to the U-field two-choice box containing two circular wire empty cages ( $8 \mathrm{~cm}$ in diameter) for $5 \mathrm{~min}$. Five minutes later, the rat was placed in the center of the box again and allowed to freely explore a wire cage containing a social target (stranger; same strain, sex, and age) or an empty wire cage for 5 min (Fig. 5I).

To assess social approach, we measured the time spent touching the social target or empty wire cage in a test phase. Touching behavior was defined as the animal directing its nose toward or its forelimbs touching the wire cage. The apparatus was cleaned with $70 \%$ alcohol and air-dried prior to each trial.

\section{Contextual fear conditioning}


To evaluate the longer retention of contextual memory, we administered contextual fear conditioning using the conditioning chamber described above. Under audio-visual recording (IXY3, Canon Inc, Tokyo, Japan), rats were allowed to explore for $3 \mathrm{~min}$. Then, as the aversive unconditioned stimulus, we delivered foot shocks three times ( $0.8 \mathrm{~mA}, 2 \mathrm{~s}$ duration). Subsequently, the rats were allowed to recover for $30 \mathrm{~s}$ in the conditioning chamber and returned to their home cage. Twenty-four hours later, the rats were again placed in the conditioning chamber, and spontaneous behaviors were monitored for a 5 -min period. To assess conditioning, we measured the time spent freezing per every $30 \mathrm{~s}$ of the testing period. The time spent freezing in the chamber was considered the measure of contextual learning. Freezing behavior was defined as cessation of all but respiratory movements [9].

\section{Object recognition task}

In the habituation phase, rats were placed in the center of an empty open field box (length: $45 \mathrm{~cm}$; width: $45 \mathrm{~cm}$; height: $45 \mathrm{~cm}$ ) and allowed to explore the box for $5 \mathrm{~min}$. In the sample phase, we placed two identical objects in the box. We placed the rats in the center of the open field box again and allowed them to explore for $5 \mathrm{~min}$. Five minutes after the sample phase, we exchanged one of the familiar objects with a new object. In the testing phase, we placed the rats in the center of the open field box and allowed them to explore for $5 \mathrm{~min}$. The apparatus was cleaned with $70 \%$ alcohol and air-dried prior to the commencement of each trial for each rat. To assess novel object memory, we measured the time spent touching a novel/familiar object during the test phase. Touching behavior was defined as the animal directing its nose toward or its forelimbs touching the object. Any other touching behavior, such as resting against the object, was not considered as touching $[9,86]$.

\section{Object-in-place task}

Prior to the task, the rats were habituated to the empty open field box for $5 \mathrm{~min}$. In the sample phase, we placed four different objects $(A, B, C$, and $D)$ in the corners of the arena, respectively. The rats were then placed in the center of the arena and allowed to explore for $5 \mathrm{~min}$. During the 5 -min delay period, all of the objects were cleaned with alcohol, to remove olfactory cues. In the test phase, the positions of two of the four objects were exchanged, and the rats were allowed to explore for $5 \mathrm{~min}$. The time spent touching the exchanged objects was compared with the time spent touching the unexchanged objects. We chose the exchanged objects randomly.

\section{Social recognition task}

Prior to the task, the rats were habituated to the U-field two-choice box for $5 \mathrm{~min}$. Then, in the sample phase, each rat was placed in the center of the box and allowed to explore an unfamiliar target (same strain, age, and sex) placed in one side. Five minutes later, the rat was placed in the box again and allowed to freely explore the same target (familiar) or a stranger (novel) for $5 \mathrm{~min}$. To assess social recognition memory, we measured the time spent touching a familiar or novel social target in test phase (Fig.6D). Touching behavior was defined as the animal directing its nose toward or its forelimbs touching the object. 


\section{Y-maze spontaneous alternation}

To evaluate spatial working memory, we used a Y-maze apparatus (Fig.6E, F). The maze consisted of three arms made of gray plastic joined in the middle to form a "Y" shape (MY-10, Shinfactory, Japan). The walls of the arms had an outside slope of $76^{\circ}(12 \mathrm{~cm}$ high), allowing the rat to see distal spatial landmarks. There were no intermaze cues inside the arms.

Prior to the experiment, the rats were allowed to explore the maze for $5 \mathrm{~min}$. Then, $24 \mathrm{~h}$ after the habituation, the rats were placed in one arm again and their spontaneous behavior was recorded for 5 min. By analyzing the number and sequence of arms entered, we calculated the score as the number of alternations divided by the total alternations [22].

\section{Statistical analysis}

We used unpaired t-tests to analyze the data for mEPSCs, mIPSCs, and self-entropy. Because the selfentropy data had large variations within the group, we performed $\log (1+x)$ transformation prior to the analysis [87]. To analyze the recognition memory tasks (object recognition, object-in-place, social preference, and social recognition tasks), we used paired $t$-tests to compare the time spent in touching novel and familiar targets in test phase. To analyze other behavioral tasks (hanging wire, visual, open field, pain threshold, light-dark box, social interaction, and Y-maze spontaneous alternation tests), we used a one-way factorial ANOVA in which the between-group factors were the individual development stages. Significance was set at $P<0.05$.

\section{Results}

Rats were subjected to the inhibitory avoidance (IA) task (Fig. 1A). They crossed from a light box to a dark box, where an electric foot shock (1.6 mA, $2 \mathrm{~s})$ was delivered. Half an hour after the task, we measured the latency in the illuminated box as contextual learning performance. Figure 1B shows the latency in the training session and the retrieval test. Two-way ANOVA revealed a significant interaction $\left(F_{3,33}=4.73, P=0.0075\right)$ and a main effect of developmental stage $\left(F_{1,33}=55.22, P<0.0001\right)$ and training $\left(F_{3,33}=3.922, P=0.0169\right)$. The training failed to increase the latency at 2 weeks (Fig. 1B). Although the rats at 8 weeks showed the highest performance after training $(462.2 \pm 63.1 \mathrm{~s}, \mathrm{n}=10)$, they exhibited difficulty in retrieving the memory if they trained at 2 weeks $(36.8 \pm 10.1 \mathrm{~s}, \mathrm{n}=6)$.

To analyze training-induced synaptic plasticity, we recorded miniature excitatory postsynaptic currents (mEPSCs) or miniature inhibitory postsynaptic current (mIPSCs) in the presence of $0.5 \mu \mathrm{M}$ tetrodotoxin in the dorsal hippocampus (Fig. 2A). By changing the membrane potential, we sequentially recorded mEPSCs (at $-60 \mathrm{mV}$ ) and mIPSCs (at $0 \mathrm{mV}$ ) from the same neuron, as reported previously [23]. We confirmed that the mEPSC and mIPSC events were clearly blocked by bath treatment with an AMPA receptor blocker (CNQX) or a $\mathrm{GABA}_{A}$ receptor blocker (bicuculline). The postsynaptic currents are thought to correspond to the response elicited by a single vesicle of glutamate or GABA [26]. In contrast, the number of synapses affects the frequency of events. 
The strength of AMPA receptor-mediated excitatory input vs. GABA $A$ receptor-mediated inhibitory input was measured in each neuron and plotted two dimensionally (amplitude in Fig. 2B, upper panel; frequency in Fig. 2C, upper panel).

Regarding the mEPSCs, IA training significantly increased their mean amplitude at 3 and 4 weeks ( 3 weeks: $t_{102}=-2.17 ; P=0.0323 ; 4$ weeks: $t_{92}=-2.57 ; P=0.0120$, unpaired $t$-test; Fig. $2 \mathrm{D}$, left) and their frequency at 3 and 4 weeks ( 3 weeks: $t_{102}=-2.05 ; P=0.0435 ; 4$ weeks: $t_{92}=-2.53 ; P=0.0140$, unpaired $t$-test; Fig. 2E, left). Conversely, the mEPSC frequency was significantly decreased at 2 weeks $\left(t_{82}=2.77 ; P\right.$ $=0.0070$, unpaired $t$-test; Fig. 2E, left).

Regarding the mIPSCs, IA training significantly increased their mean amplitude at 4 and 8 weeks (4 weeks: $t_{92}=-3.06 ; P=0.0029 ; 8$ weeks: $t_{103}=-3.56 ; P=0.0006$, unpaired $t$-test; Fig. $2 \mathrm{D}$, right) and their frequency at 3 and 4 weeks ( 3 weeks: $t_{110}=-2.56 ; P=0.0112 ; 4$ weeks: $t_{92}=-2.82 ; P=0.0059$, unpaired $t$-test; Fig. 2E, right). Conversely, mIPSC frequency was significantly decreased at 2 weeks $\left(t_{82}=3.01 ; P=\right.$ 0.0036 , unpaired $t$-test; Fig. 2E, right). Regarding the yoked control, we previously confirmed that neither mEPSCs nor mIPSCs were changed in animals exposed to a foot shock (unpaired) or the apparatus alone (walk through), suggesting the presence of IA-learning-induced synaptic plasticity in juveniles [23].

To calculate the balance between excitatory/inhibitory (E/I) input, we divided the mean mEPSC amplitude by the mean mIPSC amplitude in individual neurons. Although the training did not change the $\mathrm{E} / \mathrm{I}$ balance at $2\left(t_{82}=0.67, P=0.51\right), 3\left(t_{102}=1.00, P=0.32\right)$, and $4\left(t_{92}=1.05, P=0.30\right)$ weeks, it clearly decreased the balance at 8 weeks exclusively $\left(t_{103}=3.25, P=0.0016\right)$.

Based on the information theory of Shannon, we calculated the appearance probability of the mean amplitudes of mEPSCs and mIPSCs. First, we identified the distribution of the appearance probability in untrained control animals (Fig. 3A, left), followed by the analysis of the cell-specific appearance probability of all recorded neurons individually (Fig. 3A, right). Each probability of a single neuron was calculated as the self-entropy and plotted two-dimensionally; e.g., a point with a high appearance probability (around the mean level of mEPSC and mIPSC amplitudes) indicated a low self-entropy, whereas a point with a very rare probability (deviated from mEPSC and mIPSC amplitudes) indicated a high self-entropy.

We used a two-dimensional kernel analysis to visualize synaptic density (Fig. 3A, lower panels). IA training clearly diversified the amount of information per neuron, which was sustained. Regarding the $\mathrm{mE}(\mathrm{I}) \mathrm{PSC}$ amplitude, the training significantly increased the self-entropy at 4 and 8 weeks (mEPSC, 4 weeks: $t_{92}=-2.43 ; P=0.0186 ; 8$ weeks: $t_{103}=-2.33 ; P=0.0220$, unpaired $t$-test; Fig. $3 \mathrm{C}$, left; mIPSC, 4 weeks: $t_{92}=-3.49 ; P=0.0008 ; 8$ weeks: $t_{103}=-3.77 ; P=0.0003$, unpaired $t$-test; Fig. $3 \mathrm{C}$, right).

For the $\mathrm{mE}(\mathrm{I}) \mathrm{PSC}$ frequency, we identified the distribution of appearance probability in untrained controls (Fig. 3B, left), followed by the analysis of the appearance probability of all recorded neurons individually. 
We found cell-specific self-entropy in all recorded neurons, with self-entropy varying from cell to cell (Fig. 3B, upper panels).

A two-dimensional kernel analysis allowed the visualization of synaptic density (Fig. 3B, lower panels). IA training diversified the amount of information per neuron, which was sustained. In the mEPSC frequency, IA training significantly increased the self-entropy at 3 and 4 weeks ( 3 weeks: $t_{102}=-2.60 ; P=0.0116 ; 4$ weeks: $t_{92}=-2.69 ; P=0.0094$, unpaired $t$-test; Fig. 3D, left). In the mIPSC frequency, the training significantly increased the self-entropy at 4 and 8 weeks ( 4 weeks: $t_{92}=-3.49 ; P=0.0008 ; 8$ weeks: $t_{103}=$ $-3.77 ; P=0.0003$, unpaired $t$-test; Fig. 3D, right).

To analyze presynaptic plasticity, we examined the paired-pulse ratio after the training (Fig. 4A). At the excitatory synapses in the apical dendrite, IA training signi $\square$ cantly increased the paired-pulse ratio at 3 and 4 weeks, whereas the ratio was decreased at 2 weeks ( 2 weeks: $t_{62}=2.36 ; P=0.0224 ; 3$ weeks: $t_{62}=$ $-2.36 ; P=0.0214 ; 4$ weeks: $t_{75}=-2.79 ; P=0.0066$, unpaired $t$-test; Fig. $\left.4 \mathrm{~A}, \mathrm{~B}\right)$. At the synapses in the basal dendrite, the training decreased the paired-pulse ratio at 2 weeks $\left(t_{51}=4.61 ; P<0.0001\right.$, unpaired $t$ test; Fig. 4C).

At the inhibitory synapses in the apical dendrite, the training signi $\square$ cantly decreased the paired-pulse ratio at 4 weeks $\left(t_{65}=2.03 ; P=0.0468\right.$, unpaired $t$-test; Fig. $\left.4 \mathrm{~A}, \mathrm{~B}\right)$. At the synapses in the basal dendrite, the training signi $\square$ cantly increased the ratio at 4 and 8 weeks ( 4 weeks: $t_{64}=-2.21 ; P=0.0335 ; 8$ weeks: $t_{54}=$ $-2.09 ; P=0.0410$, unpaired $t$-test; Fig. $4 \mathrm{C}$ ). These results suggest that the training increased presynaptic glutamate release at 2 weeks, but decreased it at 3 and 4 weeks.

Early-life physiological functions may affect latency in the IA task. To rule out this possibility, we evaluated several physiological functions using the visual placing response, hanging wire, open field, flinch/jump, and light-dark box tests.

In the visual placing test, one-way ANOVA showed no significant main effect of development $\left(F_{3,27}=\right.$ $0.51, P=0.68)$, indicating the presence of basic visual function at 2 weeks. In the hanging wire test, oneway ANOVA showed a significant main effect $\left(F_{3,30}=13.140, P<0.0001\right)$, and a post-hoc analysis showed that the latency to fall was shorter at 3,4 and 8 weeks than it was at 2 weeks (vs. 3 weeks: $P=$ 0.0002 ; vs. 4 weeks: $P<0.0001$; vs. 8 weeks: $P=0.0001$; Fig. $5 \mathrm{~A}$ ).

One-way ANOVA of the open field test results showed a significant main effect associated with the centercircle latency $\left(F_{3,28}=3.81, P=0.0224\right)$, and a post-hoc analysis showed that the latency in the center circle of the open field was shorter at 3, 4 and 8 weeks than it was at 2 weeks (Fig. 5B). Conversely, regarding the traveled distance test, one-way ANOVA showed a significant main effect of traveled distance $\left(F_{3,27}=19.397, P<0.0001\right)$, and a post-hoc analysis showed that the traveled distance in the open field was longer at 3,4 and 8 weeks than it was at 2 weeks (vs. 3 weeks: $P<0.0001$; vs. 4 weeks: $P<$ 0.0001 ; vs. 8 weeks: $P=0.0002$; Fig. 5 C). 
Pain sensitivity was evaluated using the flinch/jump test. One-way ANOVA showed no significant main effect of development (flinch: $F_{3,30}=1.47, P=0.24$; Fig. 5D; and jump: $F_{3,30}=0.94, P=0.4351$; Fig. 5E), showing sufficient pain sensitivity at 2 weeks. The current threshold of vocalization at 3 weeks was more sensitive to foot shock than it was at 2 weeks $\left(F_{3,30}=4.73, P=0.0089 ; 2\right.$ vs. 3 weeks: $P=0.0037$ in posthoc analysis; Fig. 5F).

To evaluate anxiety and innate curiosity about a novel environment, we used the light-dark box test (Fig. 5G). One-way ANOVA showed a significant main effect of development $\left(F_{3,29}=5.97, P=0.0031\right)$, and the time in a novel environment was longer at 8 weeks than it was at 2 and 3 weeks.

To evaluate social behavior, we used the social interaction test (Fig. 5H). One-way ANOVA showed a significant main effect of development $\left(F_{3,29}=8.41, P=0.0005\right)$, and the sniffing time of the social target was shorter at 3 and 8 weeks than it was at 2 weeks. By comparing the touching time of a social target with an empty cage, we evaluated social preference. The touching time of social target was longer at 4 and 8 weeks, but not at 2 and 3 weeks ( 4 weeks: $t_{7}=-5.92 ; P=0.00059 ; 8$ weeks: $t_{7}=-8.46 ; P=0.00006$, paired $t$-test; Fig. 5I).

To analyze further the retention of contextual memory, we compared the performance in the retrieval test at $24 \mathrm{~h}$ after the training session in contextual fear conditioning. In contextual fear conditioning, two-way ANOVA revealed a significant interaction $\left(F_{3,25}=46.48, P<0.0001\right)$ and a main effect of learning $\left(F_{1,25}=\right.$ 264.28, $P<0.0001)$ and developmental stage $\left(F_{3,25}=22.41, P<0.0001\right.$; Fig. 6A $)$. A significant extension of freezing time was observed after 3 weeks of age (3 weeks: $P<0.0001$; 4 weeks: $P<0.0001 ; 8$ weeks: $P$ $=0.0001$ in post-hoc analysis), which provided further evidence of the existence of a critical period for this phenomenon.

To evaluate cognitive functions, we used the object recognition, object-in-place, and social recognition tasks. In the object recognition task, the training increased the touch time of a novel object at 3 and 4 weeks, but not at 2 weeks ( 3 weeks: $t_{6}=-2.48 ; P=0.0476 ; 4$ weeks: $t_{7}=3.20 ; P=0.0150,8$ weeks: $t_{7}=$ 3.48; $P=0.0102$, paired $t$-test; Fig. 6B). In the object-in-place task, the training significantly increased the touch time of the exchanged objects only at 8 weeks $\left(t_{7}=4.35 ; P=0.0033\right.$, paired $t$-test; Fig. $\left.6 \mathrm{C}\right)$. In the social recognition task, the training increased the touch time of the novel rat at 3 and 4 weeks, but not at 2 weeks ( 3 weeks: $t_{6}=3.44 ; P=0.0138 ; 4$ weeks: $t_{9}=2.27 ; P=0.0491,8$ weeks: $t_{15}=2.40 ; P=0.0296$, paired $t$-test; Fig. 6D). Thus, neither the novelty nor the changed location of the objects was identified at 2 weeks.

Spatial working memory was evaluated using the Y-maze. One-way ANOVA showed a significant main effect of development $\left(F_{3,28}=4.18, P=0.0158\right)$, and the alternation rate was higher at 8 weeks than it was at 2 weeks (Fig. 6E). The total number of arm entries did not change during development $\left(F_{3,28}=\right.$ 1.51, $P=0.237$; Fig. 6F). 


\section{Discussion}

\section{Developmental changes in memory, sensory, and motor functions}

Here, we examined the developmental changes in training-induced synaptic plasticity. At 2 weeks postnatally (postnatal day 16), but not at 3 and 8 weeks (days 22-56), rats could not maintain a memory of IA learning, suggesting an undeveloped contextual memory function in infant rats (Fig. 1 and [10]). Although rats at 2 weeks showed basic sensory/motor functions, they did not avoid aversive pain by becoming immobilized in the light box. Vision arises around postnatal days 13 and 14 [27], and sufficient pain sensitivity developed before postnatal day 16 in rats (Fig. 5D-F). Regarding motor functions, at 2 weeks, rats showed the highest grip performance on the hanging wire test (Fig. 5A). Moreover, the move into the dark box during the training session and the immobilization in the dark box in the light-dark box test suggests sufficient motor function for choosing to stay or move (Figs 1B, 5G). Regarding the emotional state, however, the open field test showed the longest center-circle time at 2 weeks (Fig. 5B). At 8 weeks, rats seemed to be more exploratory (Fig. 5C, G), but also more cautious (Fig. 5B), than they were at 2 weeks. Although the unanxious emotional state observed at 2 weeks could partly have reduced IA latency, the memory deficit may not be attributed to the development of sensory/motor functions.

\section{Training-induced plasticity at excitatory synapses}

Contextual learning requires plasticity at CA1 synapses at 4 weeks $[22,23,24,25]$; however, a developmental change in learning-dependent synaptic plasticity has not been reported. IA training increased the mEPSC amplitude at 3 and 4 weeks, but not at 2 and 8 weeks (Fig. 2D), indicating the development of training-induced synaptic plasticity at excitatory synapses. Regarding the other evidence of development, naive AMPA receptor densities increased dramatically (184\%) during postnatal days $0-10$ and were stable during postnatal days 20-30 [28]. Moreover, the magnitude of the LTP at postnatal days 12-15 was almost half that at days 19-35 [29].

In rats at 4 weeks, we previously showed a training-induced increase in the postsynaptic number of AMPA receptor channels without a change in the cation current per single channel in the CA1 [25]. Moreover, regarding a causal relationship, we previously demonstrated that bilateral gene expression of GluA1containing AMPA receptor delivery blockers in the CA1 neurons impairs IA learning [22], suggesting that newly delivered GluA1-containing AMPA receptors contribute to the formation of contextual memory.

The paired-pulse analysis performed here further revealed presynaptic plasticity at excitatory synapses. In rats at 3 and 4 postnatal weeks, the paired-pulse ratio increased after IA training, indicating a decrease in presynaptic glutamate release (Fig. 4B). Because the mEPSC frequency is used as an indicator of evoked release $[30,31,32]$ or the number of functional synapses [33,34], postsynaptic plasticity may have contributed to the increase in mEPSC frequency observed at 3 and 4 weeks. In our study of the temporal dynamics, presynaptic glutamate release increased at $5 \mathrm{~min}$ but decreased at $60 \mathrm{~min}[24,35]$. The late decrease might have been associated with feedback via presynaptic NMDA receptors [36]. 
Unexpectedly, training failed to strengthen the excitatory synapses at 8 weeks (Fig. 2D, E). The number of synapses [37] and AMPA receptors [28] reach a maximum value at 4 weeks and decline slightly at 8 weeks, suggesting that synaptic elimination plays a role in the refinement of network connections [37]. Although NMDA-dependent, CaMKII-mediated synaptic strengthening through the insertion of GluA1containing AMPA receptors has been reported in rats at 3 and 4 postnatal weeks [38,39], the plasticity may be reduced in the mature nervous system. Because a 5-min exposure to an emotional experience promotes fear memory and AMPA receptor delivery in the mature hippocampus [40], the brief foot shock administered in the IA task may not be sufficient to arouse emotion and consequent AMPA receptormediated plasticity at 8 weeks (Fig. 2D, E). Consistently, a 10-min exposure to an emotional experience, such as restraint or male-female contact, clearly induced AMPA receptor-mediated plasticity in CA1 pyramidal neurons [5]. In case of fear conditioning task, genetic manipulation to visualize CA1 engram cells seems to be necessary to detect the spine-specific plasticity in adult animals [42,42].

\section{Training-induced plasticity at inhibitory synapses}

IA training also increased the mean mIPSC amplitudes at 4-8 weeks, suggesting a postsynaptic strengthening at $\mathrm{GABA}_{A}$ receptor-mediated synapses $[23,24]$. Because the task also increased mIPSC frequency at 3 and 4 weeks, it may activate silent $G A B A_{A}$ synapses, to increase the number of synapses. $A$ genetic deficiency in the $G A B A_{A}$ receptor $\beta_{3}$ subunit and the prevention of $G A B A_{A}$ receptormediated plasticity in the $C A 1$ both impair contextual learning $[23,43]$, suggesting a causal relationship between $\mathrm{GABA}_{A}$ receptor delivery and learning. Optogenetic manipulation of CA1 neurons has further revealed a timing-specific causal relationship: the inactivation of dendrite-targeting CA1 interneurons during aversive stimuli is sufficient to prevent fear learning [44]. Thus, IA training may trigger $G_{A B A}$ receptor-mediated plasticity to encode contextual memory from the juvenile to adult periods.

We recently found rapid phosphorylation of the $\operatorname{Ser}^{408-409} \mathrm{GABA}_{A}$ receptor $\beta_{3}$ subunit immediately after training [24]. In cultured neurons, $\operatorname{Ser}^{408-409}$ phosphorylation increases both the amplitude and frequency of mIPSCs by blocking clathrin-dependent endocytosis of the synaptic receptors [45]. Because local interference in Ser ${ }^{408-409}$ phosphorylation of the bilateral CA1 clearly blocked learning- and $G A B A_{A}$ receptor-mediated plasticity at CA1 synapses [24], IA training may lead to rapid phosphorylation of Ser ${ }^{408-409}$ of the $G_{A B A} \beta_{3}$ subunit, to encode the episodic experience.

\section{Decrease in excitatory/inhibitory balance in adulthood}

Although the training failed to increase the mEPSC amplitude at 8 weeks of age (Fig. 2), the animals successfully maintained the memory of the task (Fig. 1). Because mIPSC amplitude consistently increased at 4-8 weeks of age, the training decreased the excitatory/inhibitory (E/I) balance only at 8 weeks. A decrease in $\mathrm{E} / \mathrm{I}$ balance is consistently observed in other regions in adult rodents (somatosensory cortex: [46]; amygdala: [47]. In the prefrontal cortex, the mature GABAergic system of adult animals enables an enhanced inhibitory control, whereas juveniles show a higher E/I balance because of an immature GABAergic system $[48,49]$. Moreover, optogenetic elevation, but not reduction, of 
the cellular E/I balance within the mouse medial prefrontal cortex impairs cellular information processing [50]. Although the role of the cellular E/I balance remains unknown in CA1 pyramidal neurons, the decrease of the cellular E/I balance by the mature GABAergic system may play an important role in the creation of synaptic diversity for memory processing.

\section{Critical period and infant-specific synaptic depression}

The training decreased the mEPSC and mIPSC frequencies at 2 weeks exclusively (Fig. 2E), without a decrease in presynaptic glutamate/GABA release. The decrease in miniature frequency may reflect synaptic silencing, if presynaptic transmitter release is not decreased after training [51]. Regarding the underlying mechanism, activation of AMPA receptors induces silencing at immature, but not mature, synapses, thus manifesting as a decrease in mEPSC frequency, but not amplitude [52].

Long-term depression (LTD) has been investigated in neonatal-to-juvenile CA1 neurons for decades $[53,54,55,56]$. LTD induction peaks during days $12-20$, and is less effective in older animals [57]. In addition, at the inhibitory synapses, GABAergic synapses on CA1 pyramidal neurons induce LTD over days 14-21, which involves the $G_{A B A}$ receptor-dependent suppression of adenylyl cyclase [58]. Because the training decreased the frequencies of both mEPSCs and mIPSCs at 2 weeks, but increased them at 3 and 4 weeks (Fig. 2E), the training may have decreased the number of functional synapses at 2 weeks, but increased them at 3 and 4 weeks. As rats at 8 weeks exhibited difficulties in retrieving a memory that was trained at 2 weeks, critical changes in the plasticity response might play a key role in infantile amnesia.

The rapid forgetting of contextual memory in infants may be closely associated with the GABAergic system in early development (59Kim et al., 2006; 60Kim and Richardson, 2007). Regarding a causal relationship, bilateral microinjection of a $\mathrm{GABA}_{A}$ receptor inverse agonist (FG-7142) into the hippocampus recovered the rapid forgetting of contextual memory on postnatal day 18 [59], whereas the microinjection of $\mathrm{G}_{\mathrm{GABA}}$ receptor agonist (midazolam) impaired the retrieval of forgotten memory [60]. These results suggest that tonic $G_{A B A}$ receptor-mediated inhibition in infants may cause the rapid forgetting of contextual memory.

Although IA training failed to change the mEPSC amplitude on postnatal day 16 (Fig. 2), it slightly but significantly increased postsynaptic currents mediated by markers of excitatory synapses, i.e., postsynaptic density 95 (PSD-95) and AMPA, in CA1 pyramidal neurons on postnatal day 17 [61]. Because bilateral blockade of training-dependent PSD-95 induction impaired both the AMPA receptor synaptic response and infantile memory [61], AMPA-receptor-mediated plasticity may play an essential role in the maintenance of long-term memory for contextual learning at day 17.

\section{The development of performance is task-dependent}

By analyzing the performance of other hippocampal-dependent tasks (Fig. 6), we identified the taskdependent period of amnesia. Rats learned the IA, fear conditioning, and object recognition tasks after 3 
weeks of age; in contrast, they learned the object-in-place task after 8 weeks of age. In the object-in-place task using two objects, rats successfully performed the associative spatial recognition task at postnatal day 30, but not at day 24 [62]. Because rats can perform spatial tasks after postnatal days 26-27 [63], the association of place and spatial memory between objects seemed to require a longer developmental period than did the object memory alone.

The number of place cells increases during development [3]. Less than half of CA1 pyramidal neurons have formed in the place field (place-specific firings) at 2 weeks of age in rats, whereas the population has increased by up to $90 \%$ in adult animals. Because the targeted disruption of the place field impairs memory-guided spatial behavior [64], this increase may be closely associated with the development of spontaneous alternation in the Y-maze [65] (Fig. 6E, F). Moreover, approximately $75 \%$ of dorsal CA1 neurons not only process their own location, but also express the location of the other male rat in the same cage [66], suggesting the existence of a large population of junction-place cells when two adult male rats are housed in the same cage. Although the postnatal change in the population is completely unknown, the development of social behaviors (Figs $\mathbf{5 H}, \mathbf{5 I}$, and $6 \mathrm{D}$ ) suggest a possible critical period to functionalize the junction-place cells.

\section{Declarations}

Conflict of Interests: The authors have no competing financial interests to declare.

Author Contributions: D.M. and Y.S. wrote the manuscript. Y.S., D.Y. and A.M. performed the experiments. D.M. designed the study. Y.S. analyzed data for both statistics and self-entropy.

Acknowledgments: This project was supported by Grants-in-Aid for Scientific Research B (D.M.), Scientific Research C (Y.S., D.M.), and Scientific Research in Innovative Areas (D.M.), from the Ministry of Education, Culture, Sports, Science, and Technology of Japan. The authors would like to thank Enago (www.enago.jp) for the English language review.

\section{DATA STATEMENT}

The entirety of raw data from this study is available from the authors upon request.

\section{COMPETING FINANCIAL INTERESTS}

The authors declare no competing financial interests.

\section{References}

1. Scoville, W. B., and Milner, B. Loss of recent memory after bilateral hippocampal lesions. J. Neurol. Neurosurg. Psychiatry20, 11-21 (1957).

2. Mitsushima, D., Takase, K., Funabashi, T., and Kimura, F. Gonadal steroids maintain 24-h acetylcholine release in the hippocampus: organizational and activational effects in behaving rats. $J$. 
Neurosci.29, 3808-3815 (2009).

3. Wills, T. J., Cacucci, F., Burgess, N., and O'Keefe, J. Development of the hippocampal cognitive map in preweanling rats. Science328, 1573-1576 (2010).

4. Gelbard-Sagiv, H., Mukamel, R., Harel, M., Malach, R., Fried, I. Internally generated reactivation of single neurons in human hippocampus during free recall. Science 322, 96-101 (2008).

5. Ishikawa, J., Tomokage, T., and Mitsushima, D. A possible coding for experience: ripple-like events and synaptic diversity. BioRxiv,2019.12.30. (2019). https://doi.org/10.1101/2019.12.30.891259

6. Campbell, B. A., and Campbell, E. H. Retention and extinction of learned fear in infant and adult rats. J. Comp. Physiol. Psychol.55, 1-8 (1962).

7. Campbell, B. A., and Spear, N. E. Ontogeny of memory. Psychol. Rev.79, 215-236 (1972).

8. Josselyn, S. A., and Frankland, P. W. Infantile amnesia: a neurogenic hypothesis. Learn. Mem.19, 423-433 (2012).

9. Takase, K., Sakimoto, Y., Kimura, F., and Mitsushima, D. Developmental trajectory of contextual learning and 24-h acetylcholine release in the hippocampus. Sci. Rep.4, 3738 (2014). doi: 10.1038/srep03738.

10. Travaglia, A., Bisaz, R., Sweet, E. S., Blitzer, R. D., and Alberini, C. M. Infantile amnesia reflects a developmental critical period for hippocampal learning. Nat. Neurosci. 19, 1225-1233 (2016).

11. Miles, C. A study of individual psychology. Amer. J. Psychol.6, 534-558 (1893).

12. Pugh, C. R., and Rudy, J. W. A developmental analysis of contextual fear conditioning. Dev. Psychobiol.29, 87-100 (1996).

13. Alberini, C. M., and Travaglia, A. Infantile amnesia: A critical period of learning to learn and remember. J. Neurosci.37, 5783-5795 (2017).

14. Baudry, M., Arst, D. S., and Lynch, G. Increased [3H] glutamate receptor binding in aged rats. Brain Res.223, 195-198 (1981a).

15. Baudry, M., Arst, D. S., Oliver, M., and Lynch, G. Development of glutamate binding sites and their regulation by calcium in rat hippocampus. Brain Res.227, 37-48 (1981b).

16. Steward, O., and Falk, P. M. Selective localization of polyribosomes and developing synapses in the hippocampus and dentate gyrus. J. Comp. Neurol.314, 545-557 (1991).

17. Collin, C., Miyaguchi, K., and Segal, M. Dendritic spine density and LTP induction in cultured hippocampal slices. J. Neurophysiol.77, 1614-1623 (1997).

18. Hussain, R. J., and Carpenter, D. O. Development of synaptic responses and plasticity at the SC-CA1 and MF-CA3 synapses in rat hippocampus. Cell Mol. Neurobiol. 21, 357-368 (2001).

19. Cizeron, M., Qiu, Z., Koniaris, B., Gokhale, R., Komiyama, N. H., Fransen, E., and Grant, S. G. N. A brainwide atlas of synapses across the mouse lifespan. Science369, 270-275 (2020).

20. Malinow, R., and Malenka, R. C. AMPA receptor trafcking and synaptic plasticity. Annu. Rev. Neurosci.25, 103-126 (2002). 
21. Derkach, V. A., Oh, M. G., Guire, E. S., and Soderling, T. R. Regulatory mechanisms of AMP receptors in synaptic plasticity. Nat. Rev. Neurosci.8, 101-113 (2007).

22. Mitsushima, D., Ishihara, K., Sano, A., Kessels, H. W., and Takahashi, T. Contextual learning requires synaptic AMPA receptor delivery in the hippocampus. Proc. Natl. Acad. Sci. USA108, 12503-12508 (2011).

23. Mitsushima, D., Sano, A., and Takahashi, T. A cholinergic trigger drives learning-induced plasticity at hippocampal synapses. Nat. Commun.4, 2760 (2013). doi:10.1038/ncomms3760.

24. Sakimoto, Y., Kida, H., and Mitsushima, D. Temporal dynamics of learning-promoted synaptic diversity in CA1 pyramidal neurons. FASEB J.33, 14382-14393 (2019a).

25. Sakimoto, Y., Mizuno, J., Kida, H., Kamiya, Y., Ono, Y., and Mitsushima, D. Learning promotes subfieldspecific synaptic diversity in hippocampal CA1 neurons. Cereb Cortex29, 2183-2195 (2019b). doi:10.1093/cercor/bhz022, 2019.

26. Pinheiro, P. S., and Mulle, C. Presynaptic glutamate receptors: physiological functions and mechanisms of action. Nat. Rev. Neurosci.9, 423-436 (2008).

27. Schneider, T., and Prezewlocki, R. Behavioral alterations in rats prenatally exposed to valproic acid: animal model of autism. Neuropsychopharmacology30, 80-89 (2005).

28. Behuet, S., Cremer, J. N., Cremer, M., Palomero-Gallagher, N., Zilles, K., and Amunts, K. Developmental changes of glutamate and GABA receptor densities in wistar rats. Front. Neuroanat.13, 100 (2019).

29. Cao, G., and Harris, K. M. Developmental regulation of the late phase of long-term potentiation (LLTP) and metaplasticity in hippocampal area CA1 of the rat. J. Neurophsiol. 107, 902-912 (2012).

30. Bolshakov, V. Y., Golan, H., Kandel, E. R., and Siegelbaum, S. A. Recruitment of new sites of synaptic transmission during the cAMP-dependent late phase of LTP at CA3-CA1 synapses in the hippocampus. Neuron 19, 635-651 (1997).

31. Prange, $\mathrm{O}$, and Murphy, T. H. Correlation of miniature synaptic activity and evoked release probability in cultures of cortical neurons. J. Neurosci.19, 6427-6438 (1999).

32. Liao, D., Scannevin, R. H., and Huganir, R. Activation of silent synapses by rapid activity-dependent synaptic recruitment of AMPA receptors. J. Neurosci.21, 6008-6017 (2001).

33. Isaac, J. T., Nicoll, R. A., and Malenka, R. C. Evidence for silent synapses: implications for the expression of LTP. Neuron15, 427-434 (1995).

34. Wierenga, C. J., Ibata, K., and Turrigiano, G. G. Postsynaptic expression of homeostatic plasticity at neocortical synapses. J. Neurosci.25, 2895-2905 (2005).

35. Paw-Min-Thein-Oo, Sakimoto, Y., Kida, H., and Mitsushima, D. Proximodistal heterogeneity in learning-promoted pathway-specific plasticity at dorsal CA1 synapses. Neuroscience437, 184-195 (2020).

36. Padamsey, Z., Tong, R., and Emptage, N. Glutamate is required for depression but not potentiation of long-term presynaptic function. eLife 6, e29688 (2017). 
37. Lohmann, C., and Kessels, H. W. The developmental stage of synaptic plasticity. J. physiol.592, 1331 (2014).

38. Lee, H. K., Barbarosie, M., Kameyama, K., Bear, M. F., and Huganir, R. L. Regulation of distinct AMPA receptor phosphorylation sites during bidirectional synaptic plasticity. Nature405, 955-959. (2000).

39. Yu, S. Y., Wu, D. C., Liu, L., Ge, Y., and Wang, Y. T. Role of AMPA receptor trafficking in NMDA receptordependent synaptic plasticity in the rat lateral amygdala. J. neurochem.106, 889-899 (2008).

40. Hu, H., Real, E., Takamiya, K., Kang, M. G., Ledoux, J., and Huganir, R. L. Emotion enhances learning via norepinephrine regulation of AMPA-receptor trafficking. Cel/131, 160-173 (2007).

41. Matsuo, N., Reijmers, L., and Mayford, M. Spine-type-specific recruitment of newly synthesized AMPA receptors with learning. Science319, 1104-1107 (2008).

42. Choi, J. H., Sim, S. E., Kim, J. I., Choi, D. I., Oh, J., Ye, S., Lee, J., Kim, T., Ko, H. G., Lim, C. S., and Kaang, B. K. Interregional synaptic maps among engram cells underlie memory formation. Science360, 430435 (2018).

43. DeLorey, T. M., Handforth, A., Anagnostaras, S. G., Homanics, G. E., Minassian, B. A., Asatourian, A., Fanselow, M. S., Delgao-Escueta, A., Ellison, G. D., and Olsen, R. W. Mice lacking the $\beta_{3}$ subunit of the $\mathrm{GABA}_{\mathrm{A}}$ receptor have the epilepsy phenotype and many of the behavioral characteristics of angelman syndrome. J. Neurosci. 18, 8505-8514 (1998).

44. Lovett-Barron, M., Kaifosh, P., Kheirbek, M. A., Danielson, N., Zaremba, J. D., Reardon, T. R., Turi, G. F., Hen, R., Zemelman, B. V., and Losonczy, A. Dendritic inhibition in the hippocampus supports fear learning. Science343, 857-863 (2014).

45. Kittler, J. T., Chen, G., Honing, S., Bogdanov, Y., McAinsh, K., Arncibia-Carcamo, L. A., Jovanovic, J. N., Pangalos, M. N., Haucke, V., Yan, Z., and Moss, S. J. Phospho-dependent binding of the clathrin AP2 adaptor complex to $\mathrm{GABA}_{\mathrm{A}}$ receptors regulates the efficacy of inhibitory synaptic transmission. Proc. Natl. Acad. Sci. USA102, 14871-14876 (2005).

46. Han, K., Lee, M., Lim, H. K., Jang, M. W., Kwon, J., Lee, C. J., Kim, S. G., and Suh, M. Excitationinhibition imbalance leads to alteration of neuronal coherence and neurovascular coupling under acute stress. J. Neurosci.40, 9148-9162 (2020).

47. Wang, G. Y., Zhu, Z. M., Cui, S., and Wang, J. H. Glucocorticoid induces incoordination between glutamatergic and GABAergic neurons in the amygdala. PloS One11, e0166535 (2016).

48. Selemon, L. D. A role for synaptic plasticity in the adolescent development of executive function. Transl. Psychiatry 3, e238 (2013).

49. Page, C. E., Alexander, J., Shepard, R., and Coutellier, L. Npas4 deficiency interacts with adolescent stress to disrupt prefrontal GABAergic maturation and adult cognitive flexibility. Genes Brain Behav.17, e12459 (2018).

50. Yizhar, O., Fenno, L. E., Prigge, M., Schneider, F., Davidson, T. J., O’Shea, D. J., Sohal, V. S., Goshen, I., Finkelstein, J., Paz, J. T., Stehfest, K., Fudim, R., Ramakrishnan, C., Huguenard, J. R., Hegemann, P., 
and Deisseroth, K. Neocortical excitation/inhibition balance in information processing and social dysfunction. Nature477, 171-178 (2011).

51. Mateos, J. M., Luthi, A., Savic, N., Stierli, B., Streit, P., Gahwiler, B. H., and Mckinney, R. A. Synaptic modifications at the CA3-CA1 synapses after chronic AMPA receptor blockade in rat hippocampal slices. J. Physiol.15, 129-138 (2007).

52. Wasling, P., Stranderg, J., and Hanse, E. AMPA receptor activation causes silencing of AMPA receptormediated synaptic transmission in the developing hippocampus. PloS One 7, e34474 (2012). doi: 10.1371/journal.pone.0034474.

53. Dudek, S. M., and Bear, M. F. Homosynaptic long-term depression in area CA1 of hippocampus and effects of N-methyl-D-aspartate receptor blockade. Proc. Natl. Acad. Sci. USA89, 4364-4367 (1992).

54. Mulkey, R. M., and Malenka, R. C. Mechanisms underlying induction of homosynaptic long-term depression in area CA1 of the hippocampus. Neuron9, 967-975 (1992).

55. Mulkey, R. M., Herron, C. E., and Malenka, R. C. An essential role for protein phosphatases in hippocampal long-term depression. Science261, 1051-1055 (1993).

56. Bolshakov, V. Y., and Siegelbaum, S. A. Postsynaptic induction and presynaptic expression of hippocampal long-term depression. Science264, 1148-1152 (1994).

57. Kemp, N., McQueen, J., Faulkes, S., and Bashir, Z. I. Different forms of LTD in the CA1 region of the hippocampus: role of age and stimulus protocol. Eur. J. Neurosci.12, 360-366. (2000).

58. Jappy, D., Valiullina, F., Draguhn, A., and Rozov, A. GABA $A$ receptor-dependent long-term depression at hippocampal synapses between CB1-positiveinterneurons and CA1 pyramidal cells. Front. Cell Neurosci.10, 4. (2016).

59. Kim, J. H., McNally, G. P., and Richardson, R. Recovery of fear memories in rats: role of gamma-amino butyric acid (GABA) in infantile amnesia. Behav. Neurosci.120, 40-48 (2006).

60. Kim, J. H., and Richardson, R. Immediate post-reminder injection of gamma-amino butyric acid (GABA) agonist midazolam attenuates reactivation of forgotten fear in the infant rat. Behav. Neurosci.121, 1328-1332 (2007).

61. Bessieres, B., Travaglia, A., Mowery, T. M., Zhang, X., and Alberini, C. M. Early life experiences selectively mature learning and memory abilities. Nat. Commun.11, 628 (2020). doi:10.1038/s41467020-14461-3.

62. Ainge, J. A., and Langston, R. F. Ontogeny of neural circuits underlying spatial memory in the rat. Front. Neural. Circuits6, 8 (2012).

63. Akers, K. G., Candelaria-Cook, F. T., Rice, J. P., Johnson, T. E., and Hamiton, D. A. Delayed development of place navigation compared to directional responding in young rats. Behav. Neurosci.123, 267275 (2009).

64. Robinson, N. T. M., Descamps, L. A. L., Russell, L. E., Buchholz, M. O., Bicknell, B. A., Antonov, G. K., Lau, J. Y. N., Nutbrown, R., Schmidt-Hieber, C., and Hausser, M. Targeted activation of hippocampal place cells drives memory-guided spatial behavior. Cel/183, 1586-1599 (2020). 
65. Douglas, R. J., Peterson, J. J., Douglas, D. P. The ontogeny of a hippocampus-dependent response in two rodent species. Behav. Biol.8, 27-37 (1973).

66. Danjo, T., Toyoizumi, T., and Fujisawa, S. Spatial representations of self and other in the hippocampus. Science359, 213-218 (2018).

67. Kida, H., Sakimoto, Y., and Mitsushima, D. Slice patch clamp technique for analyzing learninginduced plasticity. J. Vis. Exp.129, e55876 (2017). doi:10.3791/55876.

68. Kida, H., Tsuda, Y., Ito, N., Yamamoto, Y., Owada, Y., Kamiya, Y., and Mitsushima, D. Motor training promotes both synaptic and intrinsic plasticity of layer II/III pyramidal neurons in the primary motor cortex. Cereb Cortex26, 3494-3507 (2016).

69. Paxinos, G., and Watson, C. The Rat Brain in Stereotaxic Coordinates, Ed 4 San Diego: Academic. (1998).

70. Rogers, C. J., and Hunter, B. E. Chronic ethanol treatment reduces inhibition in CA1 of the rat hippocampus. Brain Res. Bull.28, 587-592 (1992).

71. Silverman, B. W. Density estimation for statistics and data analysis. Monographs on statistics and applied probability, Chapman and Hall, London. (1986).

72. Sheather, S. J. Density estimation. Stat. Sci.19, 588-597 (2004).

73. Shannon, C. E. A mathematical theory of communication. Bell. Syst. Tech. J.27, 379-423 (1948).

74. Pinto, L. H., and Enroth-Cugell, C. Tests of the mouse visual system. Mamm. Genome11, 531536 (2000).

75. Metz, G. A., and Schwab, M. E. Behavioral characterization in a comprehensive mouse test battery reveals motor and sensory impairments in growth-associated protein-43 null mutant mice. Neuroscience129, 563-574 (2004).

76. Sooksawate, T., Isa, K., Matsui, R., Kato, S., Kinoshita, M., Kobayashi, K., Watanabe, D., Kobayashi, K., and Isa, T. Viral vector mediated selective and reversible blockade of the pathway for visual orienting in mice. Front. Neural Circuits7, 162. (2013). doi: 10.3389/fncir.2013.00162. eCollection 2013.

77. Lehner, M., Wisłowska-Stanek, A., Maciejak, P., Szyndler, J., Sobolewska, A., Krzascik, P., and Plaznik, A. The relationship between pain sensitivity and conditioned fear response in rats. Acta Neurobiol. Exp. (Wars)70, 56-66 (2010).

78. Abada, Y. S., Nguyen, H.P., Ellenbroek, B., and Schreiber, R. Reversal learning and associative memory impairments in a BACHD rat model for Huntington disease. PLoS One8, e71633 (2013).

79. Carlile, E. L., Shirachi, D. Y., Quock, R. M. An anxiolytic-like effect of hyperbaric oxygen in the mouse light/dark exploration test. Life Sci.90, 267-271 (2012).

80. Arrant, A. E., Schramm-Sapyta, N. L., and Kuhn, C. M. Use of the light/dark test for anxietyin adult and adolescent male rats. Behav. Brain Res.256, 119-127 (2013)

81. Chen, Z., Wei, H., Pertovaara, A., Wang, J., and Carlson, S. Anxiety- and activity-related effects of paracetamol on healthy and neuropathic rats. Pharmacol. Res. Perspect.6, e00367 (2018). 
82. Vengeliene, V., Bespalov, A., Rossmanith, M., horschitz, S., Berger, S., Relo, A. L., Noori, H. R., Schneider, P., Enkel, T., Bartsch, D., Schneider, M., Behl, B., Hansson, A. C., Schloss, P., and Spanagel, R. Towards trans-diagnostic mechanisms in psychiatry: neurobehabioral profile of rats with a loss-of-function point mutation in the dopamine transporter gene. Dis. Model Mech.10, 451-461. (2017).

83. Park, J. Y., Kim, T. K., Choi, J., Lee, J. E., Kim, H., Lee, E. H., and Han, P. L. Implementation of a twodimensional behavior matrix to distinguish individuals with differential depression states in a rodent model of depression. Exp. Neurobiol. 23, 215-223. (2014).

84. Lee, Y., Kim, H., and Han, P. L. Striatal inhibition of MeCP2 or TSC1 produces sociability deficits and repetitive behaviors. Exp. Neurobiol. 27, 539-549 (2018a).

85. Lee, Y., Kim, H., Kim, J. E., Park, J. Y., Choi, J., Lee, J. E., Lee, E. H., and Han, P. L. Excessive D1 dopamine receptor activation in the dorsal striatum promotes autistic-like behaviors. Mol. Neurobiol.55, 5658-5671 (2018b).

86. Barker, G. R., Bird, F., Alexander, V., and Warburton, E. C. Recognition memory for objects, place, and temporal order: a disconnection analysis of the role of the medial prefrontal cortex and perirhinal cortex. J. Neurosci.27, 2948-2957 (2007).

87. Mitsushima, D., Hei, D., and Terasawa, E. Y-Aminobutyric acid is an inhibitory neurotransmitter restricting the release of luteinizing-hormone releasing hormone before the onset of puberty. Proc. Natl. Acad. Sci. USA91, 395-399 (1994).

\section{Figures}

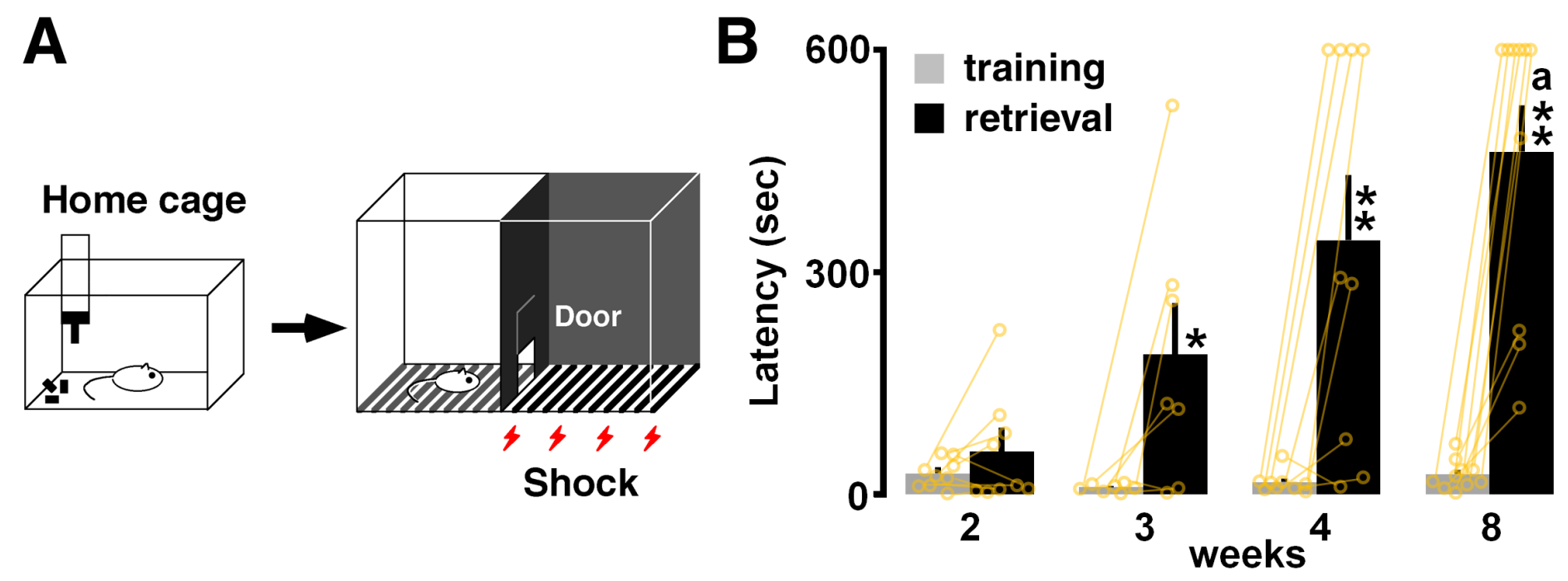

Figure 1

Inhibitory avoidance (IA) task and postnatal development of performance. (A) On the training day, we moved the rats from their home cage to the light box. (B) Thirty minutes after the training, a longer 
latency to enter the dark side of the box was observed at 3-8 weeks. Data are shown as individual points and are the mean \pm SEM. ${ }^{*} P<0.05$ vs. training. ${ }^{*} P<<0.01$ vs. training. a $P<0.05$ vs. 2 weeks.

A

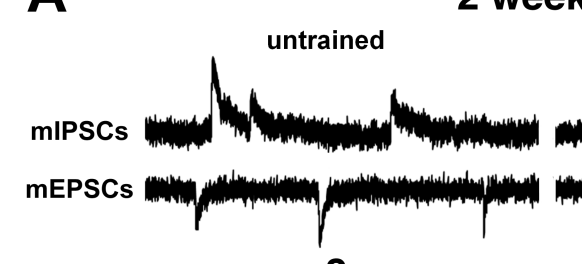

B

B
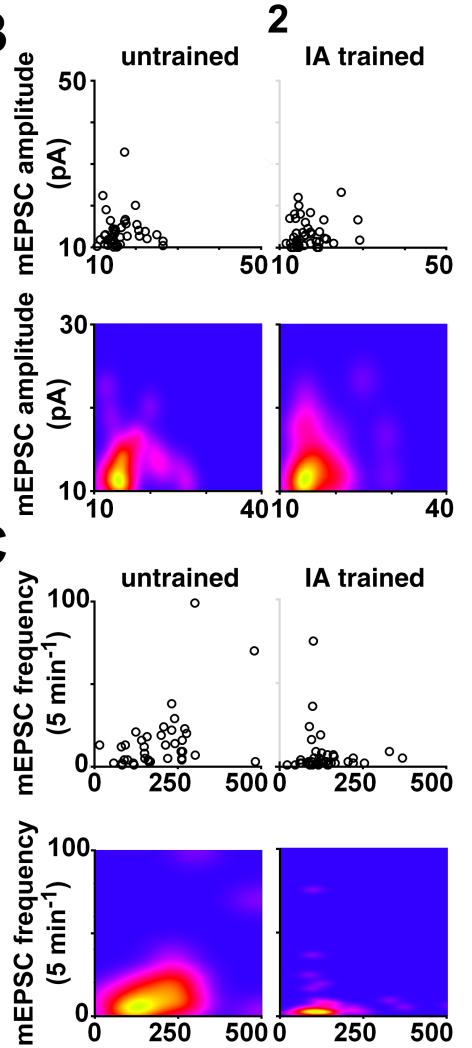

D

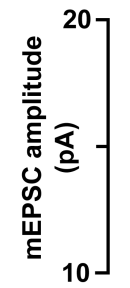

E

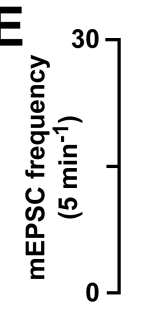

2

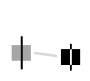

2

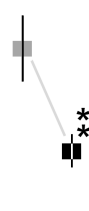

3

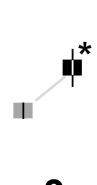

3

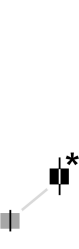

\section{4 weeks}

untrained
IA trained
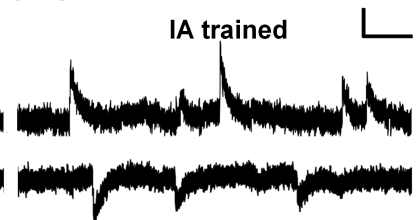

4
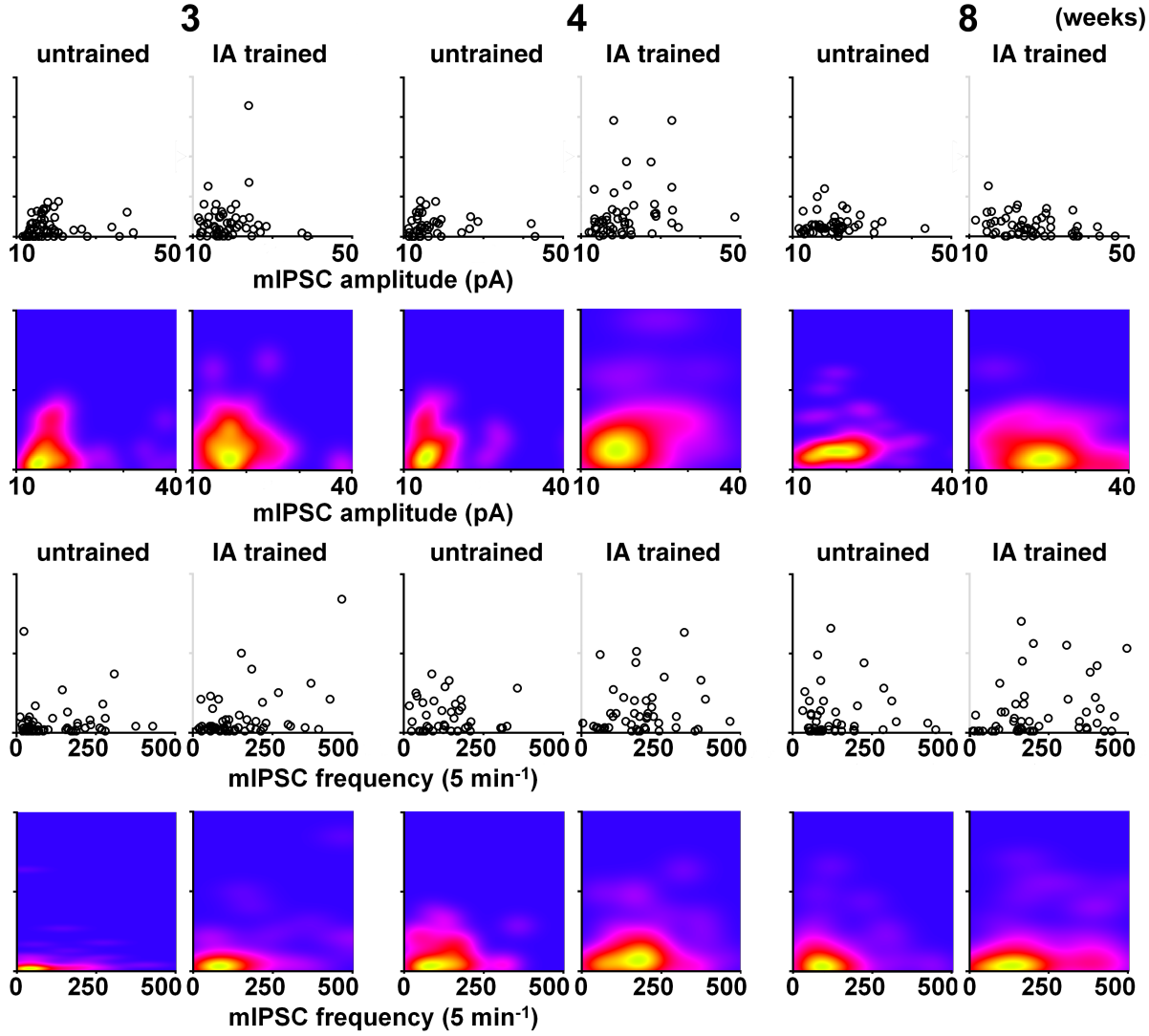

4

4

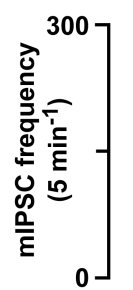

8

2

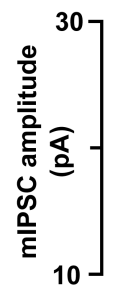

I-I

8

3

3

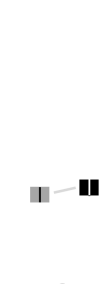

2

1-
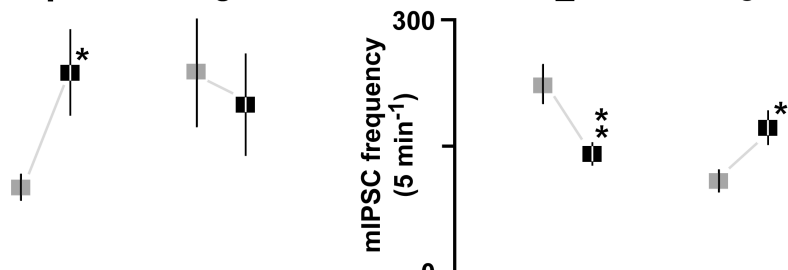

4

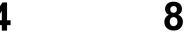

8
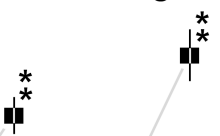

1

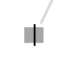

4

8

Figure 2

Postnatal development of the IA-task-induced synaptic plasticity. (A) Representative traces of mEPSCs and mIPSCs sequentially recorded in the same CA1 pyramidal neuron in the presence of tetrodotoxin (0.5 $\mu \mathrm{M})$. Vertical bar $=20 \mathrm{pA}$; horizontal bar $=50 \mathrm{~ms}$. (B) Two-dimensional plots of the mean mEPSC and 
mIPSC amplitudes in an individual neuron (upper panel), and results of the kernel density analysis visualizing the distribution of the appearance probability at any point (lower panel). (C) Two-dimensional plots of the mean mEPSC and mIPSC frequencies in an individual neuron (upper panel), and visualization of the kernel density distribution (lower panel). (D) Postnatal changes in the mean mEPSC (left) and mIPSC (right) amplitudes in untrained (gray) and trained (black) rats. The IA task increased mEPSC amplitude at 3 and 4 weeks and increased mIPSC amplitude at 4-8 weeks. (E) Postnatal changes in the mean mEPSC (left) and mIPSC (right) frequencies in untrained (gray) and trained (black) rats. The training increased the frequencies of both mEPSCs and mIPSCs at 3 and 4 weeks, and decreased these frequencies at 2 weeks. The numbers under the graphs indicate the number of neurons. The error bars indicate \pm SEM. ${ }^{\star} \mathrm{P}<0.05,{ }^{\star *} \mathrm{P}<0.01$ vs. untrained.

\section{Figure 3}

Postnatal development of the gained self-entropy in individual neurons. (A) By calculating the appearance probability of individual dots in MEPSC and mIPSC amplitudes, we calculated the selfentropy (bits) of individual neurons (upper), and visualized the kernel density distribution (lower). (B) The same process as in (A), applied for mEPSC and mIPSC frequencies, showing the self-entropy (bit) of individual neurons (upper) and the visualized kernel density distribution (lower). (C) Postnatal changes in the mean self-entropy of mEPSC (left) and mIPSC (right) amplitudes in untrained (gray) and trained (black) rats. The IA task increased the self-entropy at 4-8 weeks. A base $10 \log$ scale is used for the $Y$ axis. (D) Postnatal changes in the mean self-entropy of mEPSC (left) and mIPSC (right) frequencies. The IA task increased the self-entropy of mEPSCs (left) at 3-4 weeks, and that of mIPSCs (right) at 4-8 weeks. The numbers under the graphs indicate the number of neurons. The error bars indicate $\pm \mathrm{SEM}$. ${ }^{\mathrm{P}}$ $<0.05, * \star P<0.01$ vs. untrained.

\section{Figure 4}

Postnatal development of IA-task-induced presynaptic plasticity. (A) Representative traces of AMPA (left) and GABAA (right) receptor-mediated paired-pulse responses stimulated apical dendrites of CA1 neurons. (B) Postnatal development of the ratios by apical dendrite stimulation in untrained (gray) and trained (black) rats. (C) Postnatal development of the ratios by basal dendrite stimulation in untrained and trained rats. ${ }^{\star} P<0.05,{ }^{*} P<0.01$ vs. untrained. The numbers under the graphs indicate the number of neurons. The error bars indicate \pm SEM. 

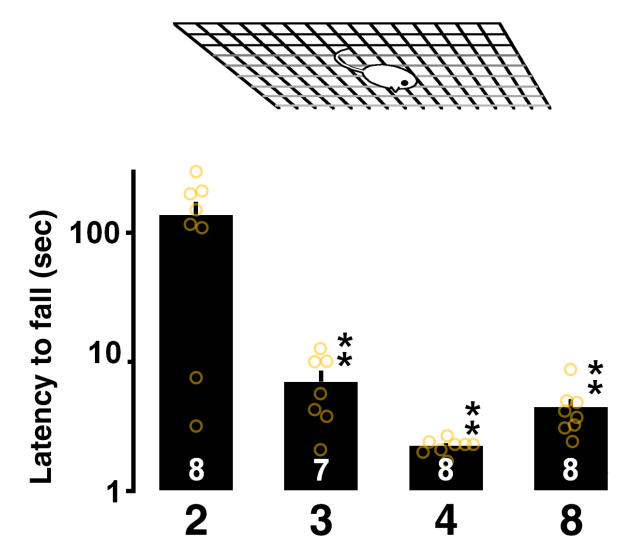

D
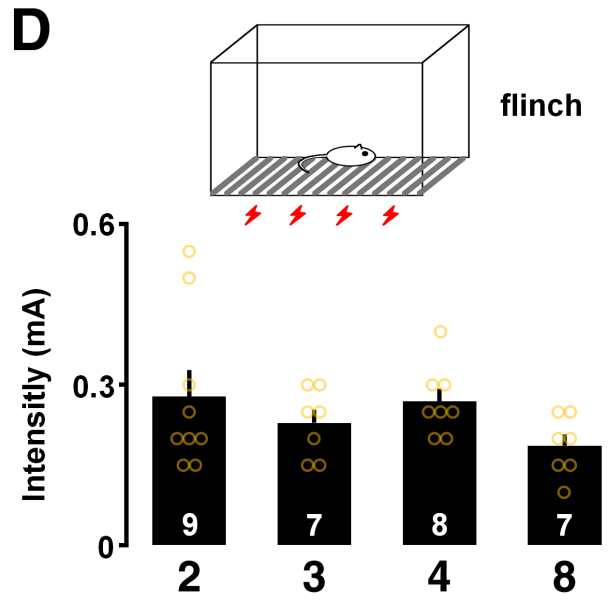

G
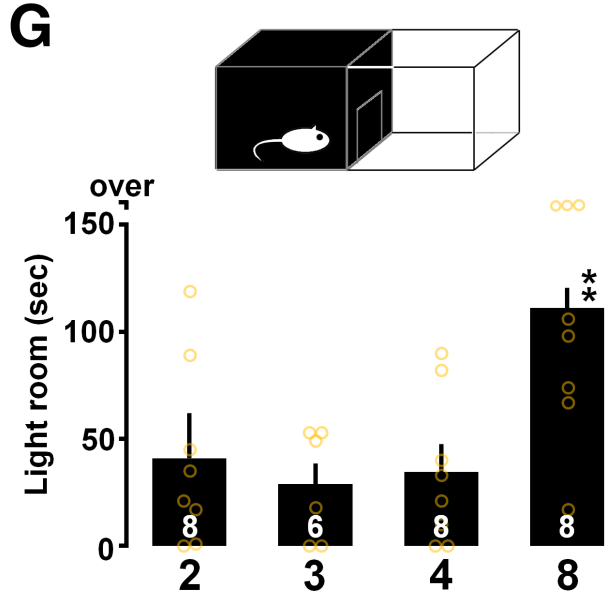
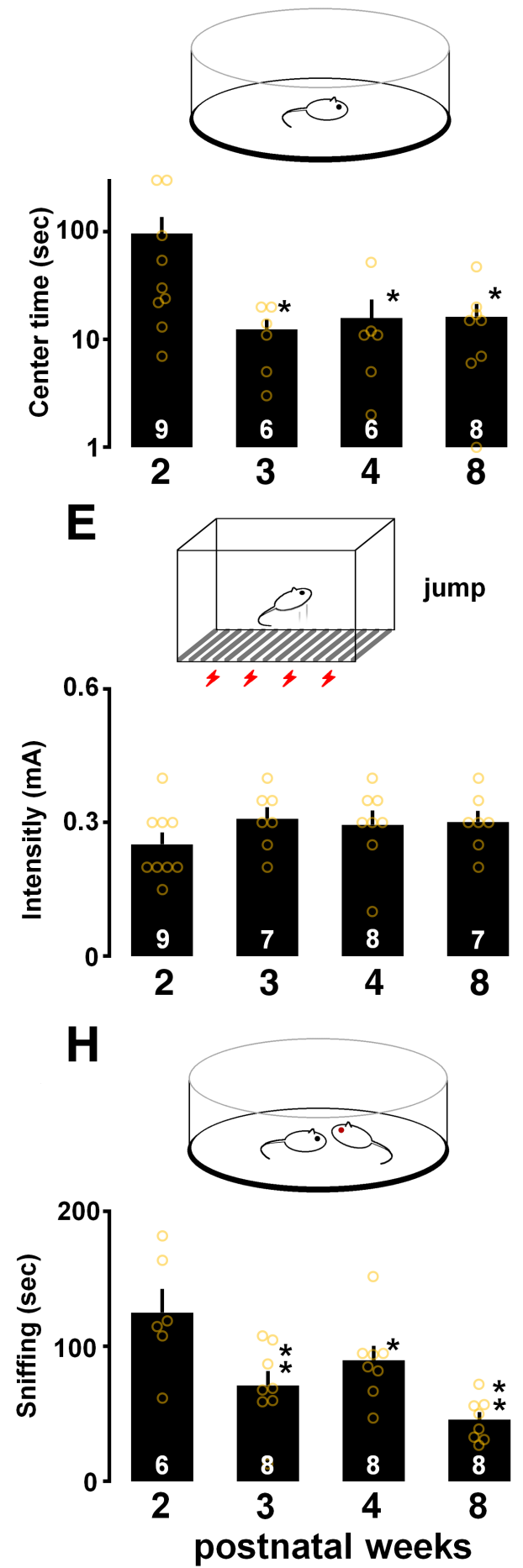
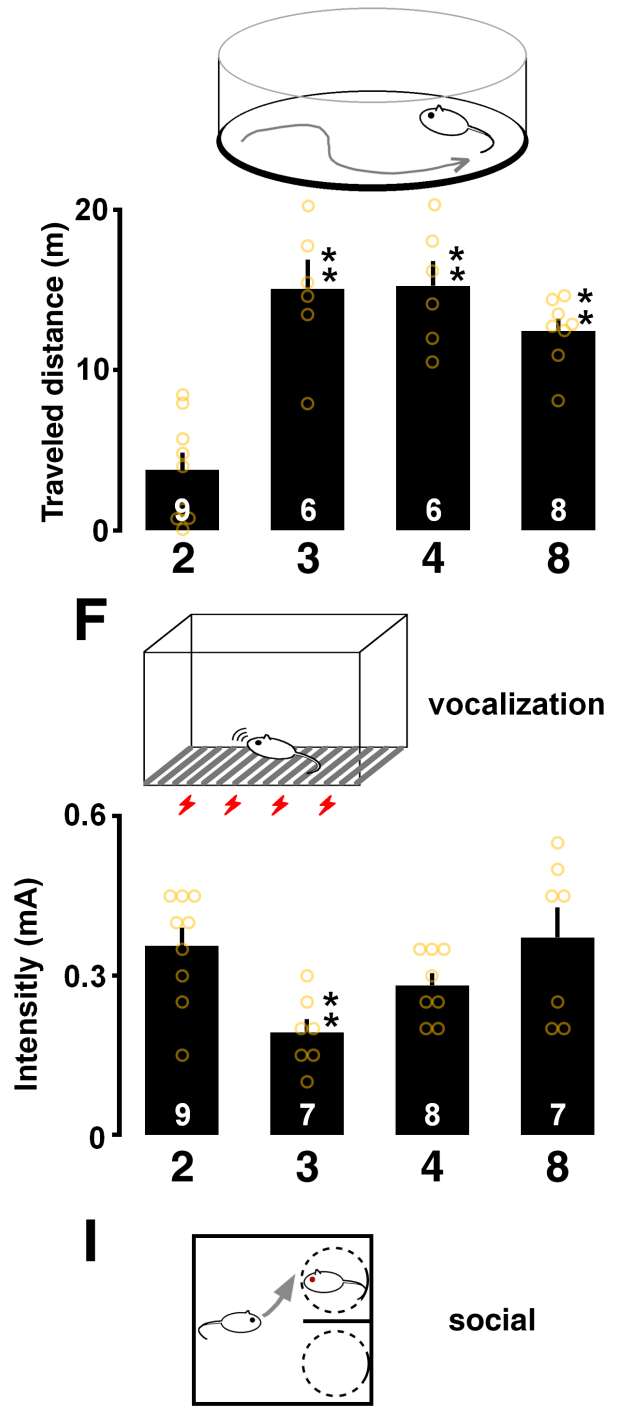

social

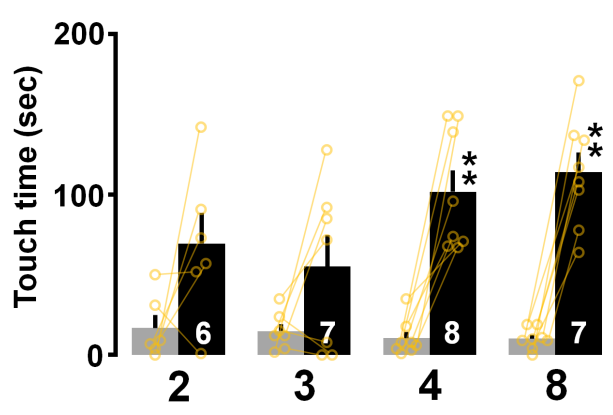

Figure 5

Postnatal changes in the sensory/motor functions and emotional state. (A) The latency to fall in the hanging wire task was shorter at 3-8 weeks than it was at 2 weeks. (B) The latency in the center circle in the open field test was shorter at 3-8 weeks than it was at 2 weeks. The traveled distance was longer at 3-8 weeks than it was at 2 weeks (C). (D, E) In the sensory test, the current intensity for the flinch or jump was not changed. (F) The current intensity for vocalization was low only at 3 weeks. (G) The time spent in the lit chamber in the light-dark box test was longer at 8 weeks than it was at 2 weeks. $(H)$ The sniffing 
time of others in social interaction was shorter at 3-8 weeks than it was at 2 weeks. (I) Exposure to a social target significantly increased touch time at 4-8 weeks. Data are shown as individual points and are the mean $\pm S E M$. ${ }^{*} P<0.05$ vs. training. ${ }^{*} P<0.01$ vs. training. a $P<0.05$ vs. 2 weeks. The number of rats is shown at the bottom of each bar.

\section{Figure 6}

Postnatal changes in other hippocampus-dependent tasks. (A) Contextual freezing across training (gray) and testing periods (black). Exposure to context significantly increased averaged freezing time at 3-8 weeks. (B) Exploration of familiar (gray) and novel objects (black) in object recognition task. Training increased the touch time of the novel object at 3-8 weeks. (C) Exploration of unchanged (gray) and exchanged objects (black) in object-in-place task. Training also increased the touch time of the exchanged objects at 8 weeks. (D) Total touch time of familiar (gray) and stranger (black) in social recognition task. Training increased the touch time of the novel target at 3-8 weeks. (E) The alternation ratio in the Y-maze test was higher at 8 weeks than it was at 2 weeks. (F) Number of total arm entries in the maze. Data are shown as individual points and are the mean $\pm S E M$. ${ }^{*} P<0.05,{ }^{*} P<0.01$. The number of rats is shown at the bottom of each bar. 